\title{
ACIDENTE COM MATERIAL BIOLÓGICO SOB A ÓTICA DOS ESTUDANTES DE ENFERMAGEM: REFLEXÕES PARA O ENSINO
}

Najara Queiroz Cardoso ${ }^{1}$, Priscilla Santos Ferreira Ream ${ }^{1}$, Camila Lucas de Souza ${ }^{1}$

Thaís de Arvelos Salgado ${ }^{1}$, Hélio Galdino Júnior ${ }^{1}$. Anaclara Ferreira Veiga Tipple ${ }^{1}$

Objetivo: identificar atividades de risco para acidentes com material biológico segundo estudantes de enfermagem e o conhecimento das medidas frente ao acidente, descrever frequência e perfil dos acidentes e identificar o atendimento pósexposição Metodologia: estudo transversal, com estudantes de enfermagem de uma instituição de ensino superior no CentroOeste, Brasil. Dados obtidos por questionário eletrônico e analisados por estatística descritiva. Resultados: Participaram 126 estudantes, maioria mulheres (96,0\%) que referiu orientação prévia acerca do risco biológico. Nenhum citou todas medidas pósexposição recomendadas. Manusear perfurocortante $(64,4 \%)$ foi o maior risco relatado e a exposição mucosa a causa de três dos quatro acidentes relatados. Desses, dois foram informados aos docentes e seguidas as condutas indicadas. Conclusão: A maioria dos estudantes reconheceu o risco no manuseio de perfurocortante. Três estudantes (2,4\%) sofreram acidente (um relatou dois) e três em mucosa. Informar ao docente foi a conduta pós-exposição mais citada, sendo que entre acidentados as condutas mais seguras foram adotadas sob orientação do docente.

Descritores: Exposição Ocupacional; Estudantes de Enfermagem; Enfermagem; Escolas de Enfermagem; Conhecimento; Riscos Ocupacionais.

\section{ACCIDENTS TO BIOLOGICAL RISK FROM THE POINT OF VIEW OF NURSING STUDENTS: REFLECTIONS ON TEACHING}

Objective: to identify risk activities for accidents with biological material in the opinion of nursing students and the knowledge of the measures against an accident, to describe the frequency and profile of the accidents and to identify the post-exposure care. Methodology: cross-sectional study with nursing students from a higher education institution in the Center-West of Brazil. Data obtained by electronic questionnaire and analyzed by descriptive statistics. Results: A total of 126 students participated, most of them women (96.0\%) who reported previous guidance on biological risk. None cited all recommended post-exposure measures. Handling sharps (64.4\%) was the most reported risk behavior and mucosal exposure was the cause of three of the four reported accidents. Of these, two were informed to the teachers and followed the indicated behaviors. Conclusion: Most students recognize the risk in activities involving sharps, but few identify them in other activities involving body fluids. Three students (2.4\%) suffered an accident (one reported two) and three in the mucosa. Informing the teacher was the most cited post-exposure behavior, and among the injured, the most secure behaviors were adopted under the guidance of the teacher.

Descriptors: Occupational Exposure; Students, Nursing; Nursing; Schools, Nursing; Knowledge; Occupational Risks.

\section{ACCIDENTES AL RIESGO BIOLÓGICO BAJO LA ÓPTICA DE LOS ESTUDIANTES DE ENFERMADO: REFLEXIONES PARA LA ENSEÑANZA}

Objetivo: identificar actividades de riesgo para accidentes con material biológico según estudiantes de enfermería y el conocimiento de las medidas frente al accidentes, describir frecuencia y perfil de los accidentes e identificar la atención post-exposición Metodología: estudio transversal, con estudiantes de enfermería en el Centro-Oeste, Brasil. Datos obtenidos por cuestionario electrónico y analizados por estadística descriptiva. Resultados: Participaron 126 estudiantes, mayoría mujeres, que han mencionado orientación previa sobre el riesgo biológico. Ninguno citó todas las medidas post-exposición recomendadas. El manejo de pinchazo fue el mayor riesgo reportado y la exposición mucosa a causa de tres de los cuatro accidentes reportados. De ellos, dos fueron informados a los docentes y seguidas las conductas indicadas. Conclusión: Tres estudiantes (2,4\%) sufrieron accidente (uno relató dos) y tres en mucosa. El informe al docente fue la conducta post-exposición más citada, siendo que entre accidentados las conductas más seguras fueron adoptadas bajo orientación del docente.

Descriptores: Exposición Ocupacional; Estudiantes de Enfermería; Enfermería; Facultades de Enfermería; Conocimiento; Riesgos Laborales

Universidade Federal de Goiás/FEN.

Autor correspondente: Camila Lucas de Souza. E-mail: mila_lsouza@hotmail.com

2 I Enferm Foco [Internet]. 2019;10(3): 2-8. 


\section{INTRODUÇÃO}

Os acidentes de trabalho com exposição a material biológico (MB) são frequentes entre os trabalhadores da área da saúde, devido ao manejo rotineiro de instrumentos perfurocortante e fluidos corporais nas atividades de cuidado à saúde (1). Os estudantes da área da saúde convivem com o mesmo risco ${ }^{(2)}$, pois durante o processo de ensinoaprendizagem também atuam diretamente no cuidado em saúde em diferentes níveis de complexidade ${ }^{(3)}$.

Entre os trabalhadores da área da saúde, a equipe de enfermagem é a que mais se acidenta com MB, por ser a categoria com maior número de profissionais e por manter o cuidado ininterrupto nos serviços de saúde ${ }^{(4)}$.

A baixa adesão às medidas de proteção e/ou o desconhecimento das medidas de biossegurança favorecem a ocorrência de acidentes com MB e podem interferir direta e/ou indiretamente na frequência e na gravidade desses ${ }^{(5)}$. Dessa forma, considera-se que a abordagem dessa temática no processo de formação acadêmica é imprescindivel para o enfrentamento do risco biológico pelos estudantes em suas atividades práticas e conhecer a epidemiologia desse agravo entre estudantes pode auxiliar as instituições de ensino e da saúde, na elaboração de estratégias preventivas.

Neste sentido, e considerando a pouca literatura sobre acidente com MB entre os estudantes de enfermagem a relação com seu conhecimento sobre esse agravo foram propostos os objetivos: identificar atividades da prática acadêmica de risco para ocorrência de acidentes com MB, na opinião de estudantes de enfermagem; identificar o conhecimento dos estudantes acerca das medidas frente a um acidente com MB, descrever a frequência e o perfil dos acidentes e identificar o atendimento pósexposição.

\section{METODOLOGIA}

\section{Tipo de estudo}

Estudo transversal e descritivo.

\section{Participantes da pesquisa}

A população foi constituida por estudantes de enfermagem. O número de estudantes matriculados era 177 . Desses, 159 atenderam à solicitação de fornecimento de endereço eletrônico para o envio do questionário. Foram feitas três tentativas de envio. Foram incluídos estudantes de enfermagem matriculados do segundo ao quinto ano, períodos nos quais predominavam as atividades práticas.

\section{Local do estudo}

Realizado em uma Instituição Pública de Ensino Superior na região Centro-Oeste brasileira no período de agosto a outubro de 2014.

\section{Coleta dos dados}

A coleta de dados foi realizada por meio de um questionário eletrônico, utilizando o software Limequery ${ }^{\circledR}$. O questionário continha questões abertas e fechadas referentes às medidas preventivas pré e pós-exposição, perfil dos acidentes, notificação e ainda as condutas/ orientações da instituição frente aos acidentes na percepção do estudante. Antecedendo à sua aplicação, o questionário foi avaliado por três profissionais com experiência na área e realizado um teste piloto com 23 egressos, da mesma instituição. A solicitação do endereço eletrônico foi realizada presencialmente, durante uma aula teórica.

\section{Procedimentos de análise dos dados}

Os dados foram analisados no software SPSS/IBM versão 19.0, por meio de estatística descritiva. As respostas oriundas das questões abertas foram transcritas na integra e identificadas pelo número do caso de 1 a 4 .

\section{Procedimentos éticos}

O estudo obteve aprovação ética (Protocolo no 414.258). O Termo de Consentimento Livre Esclarecido, as orientações sobre a pesquisa e seus objetivos compuseram a primeira página do questionário eletrônico, frente ao aceite as questões eram apresentadas.

\section{RESULTADOS}

Dos 177 estudantes elegiveis, 159 (89,8\%) atenderam à solicitação de fornecimento de endereço eletrônico, desses 11 não consentiram em participar da pesquisa e 22 não manifestaram após as três tentativas. Participaram $126(79,2 \%)$ cuja média de idade foi de 21,6 anos e 121 $(96,0 \%)$ eram do sexo feminino, cinco $(4,0 \%)$ masculino. A distribuição dos estudantes do segundo ao quinto ano do curso foi 32 (25,4\%), 30 (23,8\%), 34 (27,0\%) e $30(23,8 \%)$, respectivamente. A tabela 1 apresenta as atividades consideradas pelos estudantes de maior risco para ocorrência de acidente. 
Tabela 1. Opinião de estudantes de enfermagem do segundo ao quinto ano de formação de uma Instituição pública de ensino ( $\mathrm{N}=126)$ sobre as atividades da prática acadêmica de maior risco para a ocorrência de um acidente com material biológico. Goiânia, Goiás, Brasil, 2014

\begin{tabular}{l|c|c|c|c|c}
\hline \multirow{2}{*}{$\begin{array}{l}\text { Atividades de risco para a } \\
\text { ocorrência de acidentes }\end{array}$} & 20 ano & 30 ano & 4 ano & 50 ano & TOTAL \\
\cline { 2 - 6 } & $\mathbf{N}$ & $\mathbf{N}$ & $\mathbf{N}$ & $\mathbf{N}$ & $\mathbf{N}(\%)$ \\
\hline Manuseio com perfurocortantes & 12 & 27 & 18 & 24 & $81(64,3)$ \\
\hline $\begin{array}{l}\text { Atividades no Centro de Material } \\
\text { e Esterilização }\end{array}$ & 12 & 08 & 14 & 09 & $43(34,1)$ \\
\hline Curativo & - & 02 & 06 & 03 & $11(8,7)$ \\
\hline Procedimentos invasivos & - & - & 09 & 01 & $10(7,9)$ \\
\hline Aspiração das vias aéreas & - & 01 & 02 & 05 & $08(6,3)$ \\
\hline Exame físico & 05 & 01 & - & - & $06(4,8)$ \\
\hline Todas as atividades & 02 & - & - & - & $02(1,6)$ \\
\hline Banho no leito & - & 01 & - & - & $01(0,8)$ \\
\hline Higiene oral & - & 01 & - & - & $01(0,8)$ \\
\hline Nenhuma atividade & 02 & - & - & - & $02(1,6)$ \\
\hline Não respondeu & 01 & - & 01 & - & $02(1,6)$ \\
\hline
\end{tabular}

A maioria dos estudantes referiu ter recebido três doses da vacina contra hepatite B (110/ 87,3\%), oito (6,3\%) duas e três (2,3\%) uma dose, assim como teste de anticorpo contra o antígeno de superfície do Vírus da Hepatite $B$ (Anti-HBs) foi referido por 102 (92,7\%), sendo que 93 $(91,2 \%)$ se autodeclararam respondedores, cinco $(4,9 \%)$ não respondedores e quatro $(3,9 \%)$ não souberam infor- mar. A maioria 123 (98,4\%) afirmou orientação prévia sobre a possibilidade de contato com secreções orgânicas durante as atividades práticas. A tabela 2 apresenta as medidas pós-exposição que os estudantes referiram adotar, caso sofressem um acidente.

Tabela 2. Medidas pós-exposição referidas por estudantes de enfermagem de uma Instituição pública de ensino $(\mathrm{N}=126)$ como condutas que adotariam no caso de um acidente com material biológico. Goiânia, Goiás, Brasil, 2014

\begin{tabular}{l|c|c}
\hline Medidas pós-exposição & N & $\%$ \\
\hline $\begin{array}{l}\text { Comunicar ao professor/ chefe de enfermagem da } \\
\text { unidade }\end{array}$ & 95 & $75,4 \%$ \\
\hline Lavar com água e sabão & 74 & $58,7 \%$ \\
\hline Interromper o procedimento & 48 & $38,1 \%$ \\
\hline Notificar o acidente & 38 & $30,1 \%$ \\
\hline Identificar a pessoa-fonte & 21 & $16,6 \%$ \\
\hline Realizar sorologias & 21 & $16,6 \%$ \\
\hline Procurar assistência médica & 18 & $14,3 \%$ \\
Fazer uso de quimioprofilaxia & 08 & $6,3 \%$ \\
Receber vacina & 02 & $1,6 \%$ \\
\hline Receber imunoglobulina & 01 & $0,8 \%$ \\
\hline Solicitar apoio psicológico & 01 & $0,8 \%$ \\
\hline
\end{tabular}

Três $(2,4 \%)$ estudantes referiram ter sofrido acidente com MB, sendo que um relatou dois acidentes, os quatro casos foram caracterizados no Quadrol.

Quadro 1. Caracterização dos acidentes com material biológico referidos por estudantes de enfermagem de uma Instituição pública de ensino. Goiânia, Goiás, Brasil, 2014

\begin{tabular}{|c|c|c|c|c|}
\hline Casos de AMB* & Caso 1 & Caso 2 & Caso 3 & Caso 4 \\
\hline Ano/graduação & 29 Ano & $3 \circ$ Ano & 50 Ano & 5Ano \\
\hline Disciplina & Bases para o cuidar do indivíduo e da família II & Doenças Infecciosas & Estágio supervisionado II & Estágio supervisionado II \\
\hline Atividade & Descarte inadequado de agulha hipodérmica & $\begin{array}{l}\text { Higiene oral durante -banho } \\
\text { no leito }\end{array}$ & $\begin{array}{l}\text { Assistência em parada } \\
\text { cardiorrespiratória }\end{array}$ & $\begin{array}{c}\text { Assistência ao trabalho } \\
\text { de parto }\end{array}$ \\
\hline Tipo de Exposição & Percutâneo & Mucosa ocular & Mucosa ocular e oral & Mucosa ocular \\
\hline $\mathrm{EPI} * *$ & $\begin{array}{c}\text { Jaleco } \\
\text { Sapato fechado } \\
\text { Luvas }\end{array}$ & $\begin{array}{c}\text { Jaleco } \\
\text { Gorro } \\
\text { Sapato fechado } \\
\text { Luvas }\end{array}$ & $\begin{array}{c}\text { Jaleco } \\
\text { Gorro } \\
\text { Máscara } \\
\text { Sapato fechado } \\
\text { Luvas }\end{array}$ & $\begin{array}{c}\text { Uniforme privativo } \\
\text { Gorro } \\
\text { Sapato fechado }\end{array}$ \\
\hline Identificação da pessoa-fonte & Sim & Sim & Sim & Sim \\
\hline $\begin{array}{l}\text { Pessoa-fonte portador de doença } \\
\text { infectocontagiosa }\end{array}$ & Não & Sim & Não & Não \\
\hline Material Biológico & Sem MB aparente & Saliva & Sangue & Sangue \\
\hline Local atingido & Mão & Olho & Olho e boca & Olho \\
\hline Conduta imediata & Lavou: água e sabão & Lavou: soro fisiológico $0.9 \%$ & Lavou: água corrente & Lavou: água corrente \\
\hline Notificação & Sim & Sim & Não & Não \\
\hline
\end{tabular}


Quadro 1. Caracterização dos acidentes com material biológico referidos por estudantes de enfermagem de uma Instituição pública de ensino. Goiânia, Goiás, Brasil, 2014 (continuação)

\begin{tabular}{|c|c|c|c|c|}
\hline Casos de AMB* & Caso 1 & Caso 2 & Caso 3 & Sim \\
\hline $\begin{array}{c}\text { Atendimento médico } \\
\text { entre 2h e 72h }\end{array}$ & Sim & Sim & Não \\
\hline Uso de TARV*** & Não & Não & Não & Não \\
\hline $\begin{array}{c}\text { Realizou acompanhamento médico } \\
\text { até a alta }\end{array}$ & Não & Sim & Não \\
\hline
\end{tabular}

${ }^{*}$ Acidente com material biológico**Equipamento de proteção individual ${ }^{\star * \star}$ Terapia Antirretroviral

Questionados quais medidas poderiam ter evitado o acidente, nos três casos de exposição à mucosa (2,3 e 4) os estudantes citaram uso de óculos protetores. As orientações/ condutas recebidas da Instituição de Ensino (IE) e/ou na Unidade de Saúde após a ocorrência do acidente, citadas pelos estudantes foram:

A minha colega falou com a professora, notificamos o acidente no CAIS, fiz exame de sangue e o paciente também fez teste rápido e não tinha nada. (Caso l)

Falei com a professora e ela fez todo o acompanhamento comigo, fui para o pronto socorro da Instituição do hospital e lá fui direto pro infectologista que me acompanhou até o 30 mês e solicitou todos os exames de sangue. (Caso 2)
A faculdade não ficou sabendo, porque foi na última semana de estágio e não tive tempo de contar pro professor, porque na outra semana eu iria pro estágio em ..... [cidade do interior do estado, onde realizava estágio supervisionado]. Mas na disciplina (...) nos falam tudo o que precisamos fazer. (Caso 3)

Não comuniquei à escola, mas não foi por medo, não. Acho que passou outras coisas e eu acabei esquecendo. (Caso 4)

Com o intuito de apreender o preparo do estudante acidentado para o enfrentamento do acidente, foram agrupadas no Quadro 2 as respectivas informações, abstraídas de diferentes questões do instrumento.

Quadro 2. Situação vacinal e status sorológico, atividades práticas de risco para a ocorrência de acidente com material biológico e medidas pós-exposição referidas por estudantes vítimas de acidentes com material biológico. Goiânia, Goiás, Brasil, 2014

\begin{tabular}{|c|c|c|}
\hline $\begin{array}{c}\text { Status de imunidade para Hepatite B } \\
\text { autodeclarada por vítima }\end{array}$ & Atividades referidas como risco e Medidas pós-exposição & Medidas pós-exposição adotadas \\
\hline $\begin{array}{l}\text { G } 1^{*} \\
3 \text { doses; } \\
\text { Anti-HBs + }\end{array}$ & $\begin{array}{l}\text { Atividades que oferecem risco: } \\
\text { Banho no leito } \\
\text { Higiene oral } \\
\text { Administração de medicamentos intravenoso } \\
\text { Medidas pós-exposição referidas: } \\
\text { Parar imediatamente a assistência } \\
\text { Limpar o local com água e sabão, e no caso de mucosa soro fisiológico } \\
\text { Avisar meu supervisor/professor }\end{array}$ & $\begin{array}{l}\text { Acidente 1: } \\
\text { Parou a assistência } \\
\text { Lavou o local exposto com água e sabão } \\
\text { Comunicou a professora } \\
\text { Foi realizado teste rápido da pessoa-fonte; e sorologias no acidentado } \\
\text { Notificou o acidente } \\
\text { Acidente } 2 \text { : } \\
\text { Parou a assistência } \\
\text { Lavou o local exposto com SF } 0,9 \% \\
\text { Comunicou a professora } \\
\text { Foi realizado teste rápido da pessoa-fonte; e sorologias no acidentado } \\
\text { Notificou o acidente } \\
\text { Realizou acompanhamento clínico laboratorial até a alta }\end{array}$ \\
\hline $\begin{array}{l}\text { G } 2 * * \\
3 \text { doses; } \\
\text { Anti-HBs + }\end{array}$ & $\begin{array}{l}\text { Atividades referidas, como risco: } \\
\text { Aspiração orotraqueal } \\
\text { Punção de veias } \\
\text { Atividades no expurgo do CME**** } \\
\text { Medidas pós-exposição referidas: } \\
\text { Abandonar o que estou fazendo } \\
\text { Lavar o local imediatamente } \\
\text { Comunicar a gerência }\end{array}$ & $\begin{array}{l}\text { Parou a assistência } \\
\text { Lavou local exposto com água } \\
\text { Comunicou a chefia de enfermagem } \\
\text { Procurou oftalmologista, seguindo recomendação da CCIH }\end{array}$ \\
\hline $\begin{array}{l}\text { G } 3 * * * \\
3 \text { doses; } \\
\text { Anti-HBs+ }\end{array}$ & $\begin{array}{l}\text { Atividades referidas, como risco: } \\
\text { Sondagem (vesical e gástrica) } \\
\text { Realização de curativo } \\
\text { Assistência ao parto } \\
\text { Medidas pós-exposição referidas: } \\
\text { Parar o procedimento imediatamente } \\
\text { Lavar o local com a solução indicada (soro em mucosas ou água e sabão em pele) } \\
\text { Procurar supervisor para notificar e ser encaminhado ao local de referência }\end{array}$ & $\begin{array}{l}\text { Parou a assistência } \\
\text { Lavou local exposto com água } \\
\text { Consultou dado no prontuário } \\
\text { Realizou atendimento médico, por conta própria duas semanas após }\end{array}$ \\
\hline
\end{tabular}

* Estudante 1, vítimas dos acidentes casos 1 e 2

** Estudante 2, vítima do caso 3

*** Estudante 3, vítima do caso 4

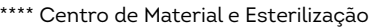




\section{DISCUSSÃO}

O predomínio do sexo feminino entre os estudantes de enfermagem encontrado nesse estudo soma-se ao perfil hegemônico entre enfermeiros(b) e estudantes da área, mesmo em outros países ${ }^{(2,3,7)}$. Trata-se de um grupo jovem (média de idade de 21,6 anos), semelhante ao encontrado na literatura entre universitários ${ }^{(7,8)}$.

O indice de vacinação completa para hepatite B $(87,3 \%)$ se assemelha a estudos entre estudantes de enfermagem no Brasi ${ }^{(9)}$ e em outros países ${ }^{(10,11)}$ e a estudos entre estudantes de outros cursos da área da saúde ${ }^{(12,13)}$. Índices superiores de vacinação já foram descritos, entre estudantes da área da saúde ${ }^{(11-13)}$. Já o índice de realização do teste anti-HBs referido $(92,7 \%)$ é muito superior a estudos entre estudantes de outros cursos da área da saúde ${ }^{(2,14)}$, podendo indicar maior acompanhamento da instituição estudada quanto à realização do exame.

No Brasil não existe política nacional de incentivo ou obrigatoriedade de vacinação para o estudante que ingressa na área da saúde. Consequentemente, amplia a responsabilidade da IE tanto pela vacinação, quanto pela confirmação da imunidade (teste anti-HBs). Merece destaque o índice de vacinação alcançado em população semelhante de uma Universidade Chilena, 98,1\%, após a implantação de um programa de gerenciamento do risco biológico ${ }^{(15)}$. Confirmando que o acompanhamento sistemático pela IE Superior aumenta a segurança do estudante que desde o início da sua formação estará se expondo ao risco durante as atividades.

A vacinação contra hepatite $B$ foi inserida no Programa Nacional de Imunização em $1998^{(16)}$, assim, por alguns anos se prevê o acesso à universidade de adultos não imunizados na infância. Ademais, o gerenciamento do risco biológico extrapola a garantia da vacinação sendo imprescindível a confirmação da resposta vacinal, o acompanhamento do estudante acidentado para o cumprimento do seguimento clínico-laboratorial, dentre outros.

O manuseio de objetos perfurocortantes foi a atividade mais indicada pelos estudantes, em todos os anos de formação, como a de maior risco para a ocorrência de acidente com MB e sabe-se que os objetos perfurocortantes são a principal causa dos acidentes entre profissionais e estudante da área da saúde (17). Reforçando a importância do processo de ensino-aprendizagem oportunizar as simulações práticas e o treinamento das habilidades técnicas para preparar o estudante, nesse caso, quanto ao manejo e descarte de perfurocortantes e o uso dos dispositivos de segurança o que pode minimizar a ocorrência e gravidade do acidente ${ }^{(18)}$.

Subentende-se que os estudantes conheciam as medidas preventivas pré e pós-exposição, pois o percentual dos que afirmaram ter informações sobre a possibilidade de entrar em contato com fluídos corporais foi alto $(98,4 \%)$. Entretanto, o contrário foi observado (Tabela 2) quanto às condutas pós-exposição; identificação da pessoa fonte e realização de sorologias, medidas definidoras de condutas protetivas, foram pouco referidas pelos estudantes.

Chama atenção o fato de a comunicação ao professor/ chefia ser a medida mais citada pelos estudantes como conduta após um acidente, sinalizando responsabilização da IE pela adoção das medidas subsequentes. Destaca-se que esta medida não está descrita prevista em manuais sobre o tema, mas já foi mencionada em estudo com estudantes de enfermagem ${ }^{(19)}$. Nesse sentido, torna-se imprescindivel o conhecimento, a atualização e a conduta dos docentes no momento de uma exposição, pois serão eles a referência para os estudantes ${ }^{(20)}$.

Sabe-se que o docente é a base sólida necessária para o desenvolvimento do futuro profissional, quem estimula as habilidades e as atitudes dos estudantes ${ }^{(21)}$. Cabe à IE investir na estabelecer mecanismos de acompanhamento dos acidentados para certificar-se que cumpram o calendário clínico-laboratorial até a alta ${ }^{(22)}$. Condutas que não apenas conferem a segurança esperada para o estudante, mas que terão influência na sua formação de profissionais capacitados e preparados para o enfrentamento do risco biológico.

Nesse sentido, merece destaque o fato de que todas as pessoas-fonte encontravam-se acessiveis para a realização de sorologias no momento do acidente, entretanto, somente quando comunicados aos docentes (casos 1 e 2) foram realizadas como recomendado. E, apenas o estudante que comunicou $\circ$ acidente para $\circ$ docente e identificou pessoa-fonte como portadora do Virus da Imunodeficiência Humana (HIV), seguiu todas as recomendações até a alta do acompanhamento. Maiores taxas de notificação e procura por atendimento clínico especializado quando as vítimas consideram o acidente como de maior gravidade foram identificadas ${ }^{(6)}$.

As atividades citadas como risco pelos estudantes acidentados incluíram aquelas que eles estavam realizando quando se acidentaram (Quadro 2). Dado que reforça a importância do aprendizado na prática clínica, os estudantes passaram a considerar "risco de acidente" as atividades que os expuseram. Reforçando o pressuposto de que quanto maior a percepção de segurança originária da prática, maior a adesão às precauções padrão(23).

Três $(75,0 \%)$ acidentes atingiram a mucosa ocular, tendo o sangue como material biológico em duas situações. Perfil diferente da maioria dos estudos, que mostram o 
predomínio de acidentes por perfurocortantes. Também é diferente do que os próprios estudantes indicaram como atividade de maior risco (manuseio de perfurocortantesTabela 2). Presume-se que o reconhecimento a priori do risco, pode induzir maior cuidado no manejo de perfurocortante. Ainda, vale considerar a maior oferta, pelos serviços de saúde, dos dispositivos de segurança.

Nos casos 2, 3 e 4 nos quais os acidentes envolveram a mucosa ocular, o uso dos óculos de proteção individual poderia tê-los evitado, como reconhecido pelas próprias vítimas, denotando o aprendizado a partir do que o estudante vivenciou na prática e mais uma vez reforça a importância de metodologias de ensino que proporcionem situações da prática clínica e da orientação e supervisão do docente quanto às medidas preventivas cabiveis em cada caso.

Foi determinante para a ocorrência do acidente que envolveu objeto perfurocortante, o descumprimento de recomendação básica da legislação brasileira, que responsabiliza o gerador do resíduo pela sua correta segregação e descarte ${ }^{(24)}$. Reitera-se que para o processo de gerenciamento de resíduos, a fase de segregação é primordial, pois quando o descarte não é realizado de forma incorreta (CASO 1), o gerador provoca risco individual e coletivo, como mostrado em estudo que identificou índices de $98,5 \%$ de exposições percutâneos entre a equipe do serviço de higiene e limpeza, 70,8\% dos acidentes relacionados ao descarte inadequado ${ }^{(25)}$.

\section{Limitações do estudo}

Participantes de uma única Instituição de Ensino Superior.

\section{Contribuições do estudo para a prática}

O estudo traz importante contribuição para a área da enfermagem por explicitar o risco biológico inerente à formação de estudantes nessa área. E, especialmente para as IE que devem prover a formação necessária à adoção de medidas preventivas pré e pós exposição a material biológico, manter seus docentes atualizados na temática e implantar estratégias de gerenciamento do risco e acompanhamento dos estudantes expostos ao risco biológico para o seguimento clínico-laboratorial quando indicado.

\section{CONCLUSÃO}

Entre estudantes de enfermagem, com predomínio de mulheres, a maioria indicou o manuseio de objetos perfurocortantes como a atividade de maior risco para a ocorrência de acidente com material biológico durante a prática acadêmica, seguida da atividade no Centro de Material e Esterilização.

A maioria dos estudantes referiu orientação prévia sobre a possibilidade de entrar em contato com secreções orgânicas nas atividades práticas e não soube indicar o conjunto de medidas esperadas frente a um acidente. A conduta mais indicada por eles após um acidente, responsabiliza a instituição de ensino pelo atendimento, "comunicar ao professor/chefia".

Três estudantes $(2,4 \%)$ referiram ter sofrido acidente com $\mathrm{MB}$, sendo que um relatou dois acidentes. Dos quatro acidentes, três foram por exposição a mucosa e poderiam ser evitados pelo uso dos óculos, segundo as próprias vítimas. Apenas um estudante realizou acompanhamento médico até a alta.

A importância dos docentes no acompanhamento do estudante acidentado pôde ser constatada pela adoção das medidas recomendadas pós-exposição quando o estudante comunicou o acidente ao docente, em contraposição à negligência a essas medidas quando não houve a comunicação. Os achados desse estudo evidenciam a importância do docente para o cumprimento das medidas pós-exposição a material biológico entre estudantes o que, necessariamente, requer formação e atualização docente acerca dessa temática e uma política de gerenciamento do risco biológico pela instituição de ensino.

\section{Contribuição dos autores}

Concepção e desenho, análise e interpretação dos dados, redação do artigo, revisão crítica, revisão final: Najara Queiroz Cardoso, Priscilla Santos Ferreira Ream, Camila Lucas de Souza, Thaís de Arvelos Salgado, Hélio Galdino Júnior, Anaclara Ferreira Veiga Tipple.

\section{Agradecimentos}

Esta pesquisa contou com Bolsa de estudos da Coordenação de Aperfeiçoamento de Pessoal de Nivel Superior (CAPES) para a primeira autora. 


\section{REFERÊNCIAS}

1. Santos Junior EP, Batista RRAM, Almeida ATF, Abreu RAA. Acidente de trabalho com material perfurocortante envolvendo profissionais e estudantes da área da saúde em hospital de referência. Rev Bras Med Trab. [Internet]. 2015 [acesso em 20 jul 2018]; 13(2). Disponivel em:http://www. anamt.org.br/site/upload_arquivos/rbmt_volume_13_n\%C2\%BA_2_2932 0161552145795186.pdf

2. Pinelli C, Neri SN, Loffredo LCM. Dental students reports of occupational exposures to potentially infectious biological material in a Brazilian School of Dentistry. Cadernos Saúde Coletiva [Internet]. 2016 [acesso em 20 jul 2018]; 24 (2). Disponivel em: http://www.scielo.br/pdf/cadsc/ v24n2/1414-462X-cadsc-24-2-162.pdf.

3. Canalli R, Moriya T, Hayashida M. Acidentes com material biológico entre estudantes de enfermagem. Revista de Enfermagem UERJ [Internet]. 2010 [acesso em 20 jul 2018]; 18(2). Disponivel em: http://www.facenf.uerj. $\mathrm{br} / \mathrm{v} 18 \mathrm{n} 2 / \mathrm{v} 18 \mathrm{n} 2 \mathrm{al6}$.pdf.

4. Carvalho DC, Rocha JC, Gimenes MCA, Santos EC, Valim MD. Work incidents with biological material in the nursing team of a hospital in MidWestern Brazil. Escola Anna Nery [Internet]. 2018 [acesso em 20 jul 2018]; 22(1). Disponivel em: http://www.scielo.br/pdf/ean/v22nl/1414-8145-ean2177-9465-EAN-2017-0140.pdf

5. Porto JS, Marziale MHP. Motivos e consequências da baixa adesão às precauções padrão pela equipe de enfermagem. Revista Gaúcha de Enfermagem [Internet]. 2016 [acesso em 20 jul 2018]: 37(2). Disponivel em: http://www.scielo.br/pdf/rgenf/v37n2/0102-6933-rgenf-1983144720160257395.pdf

6. Luize PB, Canini SRMS, Gir E, Toffano SEM. Procedures after exposure to biological material in a specialized cancer hospital. Texto \& Contexto Enfermagem [Internet]. 2015 [acesso em 20 jul 2018]; 24(1). Disponivel em: http://www.scielo.br/pdf/tce/v24nl/0104-0707-tce-24-01-00170.pdf

7. Suliman M, Al Oadire M, Alazzam M, Aloush S, Alsaraireh A, Alsaraireh FA. Students nurses' knowledge and prevalence of Needle Stick Injury in Jordan. Nurse education today [Internet]. 2018 [acesso em 20 jul 2018]; 60. Disponivel em: https://doi.org/10.1016/j.nedt.2017.09.015

8. Ximenes Neto FRG, Muniz CFF, Dias LJLF, Diogenes Júnior F, Silva MAM, Oliveira EN. Perfil sociodemográfico dos estudantes de enfermagem da Universidade Estadual Vale do Acaraú (UVA). Enferm. Foco [Internet]. 2017 [acesso em 11 maio 2019]; 8 (3): 75-79. Disponivel em: http://revista.cofen.gov.br/index. php/enfermagem/article/view/1532/404.

9. Canalli R, Moriya T, Hayashida M. Prevenção de acidentes com material biológico entre estudantes de enfermagem. Revista de enfermagem UERJ [Internet]. 2011 [acesso em 20 jul 2018]; 19(1). Disponivel em: http://www. facenf.uerj.br/v19nl/v19nlal7.pdf

10. Loulergue P. Fonteneau L. Armengaud JB, Momcilovic S, Levy-Bruhl $D$, Launay $O$, et al. Vaccine coverage of healthcare students in hospitals of the Paris region in 2009: the Studyvax survey. Vaccine [Internet]. 2013 [acesso em 20 jul 2018]; 31(26). Disponivel em: https://doi.org/10.1016/j. vaccine.2013.04.00

11. Papagiannis D, Tsimtsiou Z, Chatzichristodoulou I, Adamopoulou M. Kallistratos I, Pournaras S, et al. Hepatitis B Virus Vaccination Coverage in Medical, Nursing, and Paramedical Students: A Cross-Sectional, Multi-Centered Study in Greece. International journal of environmental research and public health [Internet]. 2016 [acesso em 20 jul 2018]; 13(3). Disponivel em: https://www.ncbi. $\mathrm{nlm}$.nih.gov/pmc/articles/PMC4808986/pdf/ijerph-13-00323.pdf

12. Andrade Neto EP, Dutra CS, Lima V. Goes P. Prevalência de acidentes ocupacionais e perfil de vacinação contra Hepatite B entre estudantes e profissionais da odontologia: um estudo piloto. Arquivos em Odontologia [Internet]. 2013 [acesso em 20 jul 2018]; 49(1). Disponivel em:https://www.researchgate.net/profile/Paula_Goes/publication/272807415_Prevalencia_ de_acidentes_ocupacionais_e_perfil_de_vacinacao_contra_Hepatite_B_ entre_estudantes_e_profissionais_da_odontologia_um_estudo_piloto/ links/58e26ld8a6fdcc4lbf99ec05/Prevalencia-de-acidentes-ocupacionais-e-perfil-de-vacinacao-contra-Hepatite-B-entre-estudantes-e-profissionais-da-odontologia-um-estudo-piloto.pdf.

13. Reis PGTA, Driessen AL, Costa ACBA, Nasr A, Collaço IA, Tomasich FDS. Perfil epidemiológico de acidentes com material biológico entre estudantes de medicina em um pronto-socorro cirúrgico. Revista do Colégio
Brasileiro de Cirurgiões [Internet]. 2013 [acesso em 20 jul 2018]: 40(4). Disponivel em: http://www.scielo.br/pdf/rcbc/v40n4/v40n4a06.pdf

14. Ghomraoui FA, Alfaqeeh FA, Algadheeb AS, Al-Alsheikh AS, Al-Hamoudi WK. Alswat KA. Medical students' awareness of and compliance with the hepatitis B vaccine in a tertiary care academic hospital: An epidemiological study. Journal of infection and public health [Internet]. 2016 [acesso em 20 jul 2018]: 9(1). Disponivel em: https://doi.org/10.1016/j.jiph.2015.06.008

15. Fica CA, Jemenao PMI, Ruiz RG, Larrondo LM, Hurtado HC, Muñoz GG, et al. Accidentes de riesgo biológico entre estudiantes de carreras de la salud: Cinco años de experiencia. Revista chilena de infectologia [Internet]. 2010 [acesso em 20 jul 2018]; 27(1). Disponivel em: https://scielo.conicyt.cl/ $\mathrm{pdf} / \mathrm{rci} / \mathrm{v} 27 \mathrm{nl} / \mathrm{art05}$.pdf

16. Ministério da Saúde. Programa Nacional de Imunizações (PNI): 40 anos. In: Secretaria de Vigilância em Saúde, Departamento de Vigilância Epidemiológica, editor. Brasilia (Brasil): Ministério da Saúde [Internet]. 2013 [acesso em 20 jul 2018]. Disponivel em: http://bvsms.saude.gov.br/bvs/publicacoes/programa_nacional_imunizacoes_pni40.pdf.

17. Bush C, Schmid K, Rupp ME, Watanabe-Galloway S, Wolford B, Sandkovsky U. Bloodborne pathogen exposures: Difference in reporting rates and individual predictors among health care personnel. American journal of infection control [Internet]. 2017 [acesso em 20 jul 2018]; 45(4). Disponivel em: https://doi.org/10.1016/j.ajic.2016.11.028

18. Carmo IC, Schiavon ICA, Oliveira EC, Campos ICMC. Segurança e enfermagem: reflexões sobre o ensino da biossegurança nos cursos de enfermagem. Scientia Tec: Revista de Educação, Ciência e Tecnologia do IFRS [Internet]. 2016 [acesso em 20 jul 2018]; 3(2). Disponivel em: https://periodicos.ifrs.edu.br/index. $\mathrm{php} /$ ScientiaTec/article/view/1524/1353.

19. Souza-Borges FR, Ribeiro LA, Oliveira LC. Occupational exposures to body fluids and behaviors regarding their prevention and post-exposure among medical and nursing students at a Brazilian public university. Revista do Instituto de Medicina Tropical de Sao Paulo [Internet]. 2014 [acesso em 20 jul 2018]; 56(2). Disponivel em: http://www.scielo.br/pdf/rimtsp/ v56n2/0036-4665-rimtsp-56-02-157.pdf

20. Morais RLGL, Tanan MS, Oliveira JS, Macedo MP, Nery AA, Matos Filho SA. Knowledge and practices of biosafety among nursing professors. Revista de Pesquisa: Cuidado é Fundamental Online [Internet]. 2017 [acesso em 20 jul 2018]; 9(1). Disponivel em: http://www.seer.unirio.br/index.php/ cuidadofundamental/article/view/5191/pdf

21. Betancourt L, Muñoz LA, Merighi MAB, Santos MF. O docente de enfermagem nos campos de prática clínica: um enfoque fenomenológico. Rev LatinoAm Enfermagem. [Internet]. 2011 [acesso em 20 jul 2018]; 19(5). Disponivel em: http://www.scielo.br/pdf/rlae/v19n5/pt_18.pdf.

22. Ministério da Saúde. Protocolo clínico e diretrizes terapêuticas para profilaxia pós-exposição (PEP) de risco à infecção pelo HIV. IST, e hepatites virais. In: Secretaria de Vigilância em Saúde Departamento de Vigilância Prevenção e Controle das Infecções Sexualmente Transmissiveis do HIV/ Aids e das Hepatites Virais, editor.: Brasilia : Ministério da Saúde [Internet]. 2017 [acesso em 18 dez 2018]. Disponivel em: http://www.aids.gov.br/pt-br/ pub/2015/protocolo-clinico-e-diretrizes-terapeuticas-para-profilaxiapos-exposicao-pep-de-risco

23. Malaguti-Toffano SE, Santos CB, Canini SRMS, Galvão MTG, Brevidelli MM, Gir E. Adesão às precauções-padrão de profissionais de enfermagem de um hospital universitário. Acta Paulista de Enfermagem [Internet]. 2012 [acesso em 20 jul 2018]; 25 (3). Disponivel em: http://www.scielo.br/pdf/ ape/v25n3/v25n3al3.pdf

24. Ministério da Saúde. Agência Nacional de Vigilância Sanitária. Resolução no 222, de 28 de março de 2018. Regulamenta as Boas Práticas de Gerenciamento dos Residuos de Serviços de Saúde e dá outras providências. Brasilia: Ministério da Saúde [Internet]. 2018 [acesso em 20 jul 2018]. Disponivel em: http://portal.anvisa.gov.br/documents/10181/3427425/ RDC_222_2018_.pdf/c5d3081d-b331-4626-8448-c9aa426ec410

25. Ream PS, Tipple AF, Salgado TA, Souza AC, Souza SM, Galdino-Junior $\mathrm{H}$, et al. Hospital housekeepers: victims of ineffective hospital waste management. Archives of environmental \& occupational health [Internet]. 2016 [acesso em 20 jul 2018]; 71(5). Disponivel em: https://doi.org/10.1080/1933 8244.2015 .1089827$. 